\section{Improving Austrian science}

SIR - As an Austrian scientist who has himself received part of his formal training in Austria and then moved on to do graduate and postgraduate work at the Massachusetts Institute of Technology in the United States, I have followed the debate on the quality of Austrian biochemical science with great interest (Nature 377, 468; 1995). But I disagree with the response from Hermann Esterbauer et al., because they do not address the cause of the current situation (Nature 379, 294; 1996).

Despite the assertion that "a fair and objective evaluation of Austria's scientific productivity and quality in comparison to its European neighbours is currently impossible", it seems to me that the beneficiaries of the current academic system just do not like being reminded of their shortcomings. A system where external faculty appointments are the exception rather than the rule has produced an environment in which dutiful service to senior faculty, internal politics and 'connections' are the hardest currency in the appointments process. The mediocre candidate who has served his way through the ranks is preferred to an ambitious external candidate with a good publication record. Positions are often advertised with such specific requirements that nobody except the 'desired' candidate will meet the demanded criteria.

The welcome move of the Fond zur Förderung der Wissenschaftlichen Forschung (FWF) to make generous grants to young investigators provides only a superficial solution to the "misguided" appointment process. In fact, as the FWF does not provide laboratory space, young researchers are often forced to trade such space for co-authorship with more senior faculty members. This approach encourages a system of career-long dependency and servitude in which one's professional future is linked to that of a senior faculty member. Progress has to come from providing autonomy and seed funding for startup laboratories able to extend their work after proven productivity, judged by an international peer review process. Young researchers should be given the opportunity to start independent groups that survive or fail on the basis of proven performance and not on how well they serve the purpose of established faculty. Resources will be diluted (as they are now) but the brightest and most talented investigators will succeed by attracting grant money and students once a truly free market of research ideas has been established.

Appointments for tenure-track positions should be reserved for researchers from other institutions and awarded on the basis of outstanding achievements. This should prevent the blatant abuse of access privileges to equipment, students and bench space and curtail the destructive intellectual inbreeding and favouritism that I consider to be the root of the problem.

Tillman U. Gerngross

Metabolix, Inc.,

303 Third Street,

Cambridge, Massachusetts 02142, USA

\section{Life on Mars?}

SIR - Having proposed that the first living organisms lived on the thermal cycling inherent to convecting hot springs, and that Martian organisms might still do $\mathrm{so}^{1}$, I strongly disagree with Newsom ${ }^{2}$. From the existence of a plausible present-day energy source it follows that "the chances of finding evidence for past life on Mars" are certainly not "extremely remote", as there is even a chance of finding life on Mars at present, albeit in a primitive form.

Irrespective of my model being right or wrong, the absence of a generally accepted standard model for the origin of life makes searches for extraterrestrial life both difficult - where and what to look for, how to recognize it? - and dangerous. Therefore, "the contamination of the Earth with living martian organisms is undoubtedly" not "unlikely". On Earth, invading species from far-away habitats have caused and still cause numerous problems. The probable lack of a good understanding of any martian organism may make its containment very difficult.

Anthonie W. J. Muller

Department of Geology

and Applied Geology,

University of Glasgow,

G12 8QQ Glasgow, UK

1. Muller, A. W. J. Prog. Biophys. molec. Biol. 63, 193-231 (1995).

2. Newsom, H. E. Nature 379, 205-206 (1996).

\section{ISI miscount?}

SIR - I am astonished that the Institute for Scientific Information (ISI) has identified a decline in internationally co-authored papers (Nature 379, 287; 1996). No explanation is given, however, for this observation.

It may very well be that the percentage of internationally co-authored papers has stabilized or even decreased. But such a trend may be an effect of database coverage, for example as a consequence of adding less-international journals.

Another explanation may have to do with the way in which the measure was constructed. ISI has counted the percentage of papers with more than one country listed among the addresses. But even if that percentage is declining, the number of countries per paper might still grow. I tested this idea by logging on to the Science Citation Index database via the Dialog system. First, I summed the number of papers for each of 22 OECD countries. This sum of so-called 'whole counts' will always, as a consequence of international co-authorships, exceed the actual number of papers. Then I retrieved the number of papers for the 22 -country set by using the boolean operator "or", which excludes double counting. This number is in fact the same as summing fractional counts - each article is counted only once. In 1980 , the ratio of whole counts (which numbered 442,828) to fractional counts $(426,009)$ was 1.039 . By 1994 , the ratio had grown steadily to $1.111(710,575 / 639,700)$. This means that international co-authorship is actually increasing and not declining.

Olle Persson

Inforsk,

Department of Sociology,

Umeå University,

S-901 87 Umeå, Sweden

\section{Little difference}

SIR - In a recent article, Graeber et al. (Nature 379, 88; 1996) suggested that hypoxia selects for cells deficient in functional p53 tumour suppressor which no longer undergo hypoxia-induced apoptosis. Since the authors demonstrated that cell viability was almost unchanged at $\mathrm{O}_{2}$ concentrations as low as $0.2 \%$ and only markedly decreased in a p53-dependent manner at $\mathrm{O}_{2}$ concentrations around $0.02 \%$ $\mathrm{O}_{2}$, we propose that anoxia (the lack of $\mathrm{O}_{2}$ ) rather than hypoxia (a reduction in $\mathrm{O}_{2}$ concentration) induces programmed cell death.

Although this might look like pure semantics, distinguishing between hypoxia and anoxia has important biological consequences: while some genes such as erythropoietin or vascular endothelial growth factor are already induced by physiological hypoxia (caused by, for example, high altitude or during development), others such as p53 are induced only by pathological anoxia (caused by, for example, ischaemia or extensive tumour growth) leading to cell death. As 'real' anoxia $\left(0 \% \mathrm{O}_{2}\right)$ is seldom achieved in biological systems, distinguishing between hypoxia and anoxia is functional rather than physical and the borders may overlap. It is comforting to know, however, that we do not turn apoptotic when we go skiing in the Swiss Alps.

Roland $\boldsymbol{H}$. Wenger

Max Gassmann

University of Zürich, Institute of Physiology,

$\mathrm{CH}-8057$ Zürich, Switzerland 